\title{
Profit efficiency among paddy farmers: a Cobb-Douglas stochastic frontier production function analysis
}

\begin{abstract}
A multiple regression model based on Stochastic Frontier Profit Function which assumed Cobb-Douglass specification form was estimated using a cross-sectional data obtained from a sample of 397 Paddy households via Multi-stage and simple random sampling techniques. Maximum likelihood estimates of the specified profit model revealed that profit efficiencies of the producers varied between $30.5 \%$ and $94.8 \%$ with a mean of $73.2 \%$ suggesting that an estimated $26.8 \%$ of the profit is lost due to a combination of technical and allocative inefficiencies in Paddy production. Results from the technical inefficiency model revealed that credit education, farming experience, extension service, MR219 seed variety, broadcast planting method, machine broadcasting method and herbicides were significant factors influencing profit inefficiency. This shows that profit inefficiency in Paddy production could be shortened significantly with improvement in the level of the above socio-economics characteristics of the sampled farmers.
\end{abstract}

Keyword: Stochastic; Profit efficiency; Cobb-Douglass; Paddy; MADA; Cross-sectional data 